УДК 811.111'42

ББК 81.432.1

DOI: https://doi.org/10.17308/lic.2021.4/3814

\title{
СООБЩЕСТВО ПРАКТИКИ КАК ИСТОЧНИК ДИСКУРСИВНО ФОРМИРУЕМОЙ НОРМЫ (НА ПРИМЕРЕ БРИТАНСКОЙ РЕЧИ ШАФЕРА)
}

\author{
А. В. Быстрых, Е. Е. Беляева \\ Воронежский государственный университет

\begin{abstract}
THE COMMUNITY OF PRACTICE AS A FRAMER OF DISCURSIVE NORMS (CASE STUDY: BEST MAN SPEECH)
\end{abstract}

\author{
A. V. Bystrykh, E. E. Belyaeva \\ Voronezh State University
}

\begin{abstract}
Аннотация: статья обращается к рассмотрению границ коммуникативной свободы говорящего в контексте британской речи шафера и механизмов, лежащих в основе избираемых оратором речевых практик. Не подвергаясь внешнему регламентированию со стороны канонических текстов и норм этикета, речь шафера в британской лингвокультуре тем не менее обнаруживает заметную однотипность в отношении конвенционально реализуемых речевых маневров. В иелях установления и анализа дискурсивно закрепляемьх за речью шафера норм в статье предлагается рассматривать участников торжественной иеремонии бракосочетания как эмергентное сообщество практики, взаимодействующее на основе бессознательно усвоенных норм ожидания, выступающих одновременно и в качестве своеобразного критерия членства сообщества, и грании уместности дискурсивного поведения его членов. На основе анализа композиционной структуры, тематического наполнения и ключевых дискурсивных стратегий 60 речей шафера в работе выявляются специфичные для данного типа публичного выступления коммуникативные выборы (маневры) говорящего, стратегически используемые им как средства управления гармонией межличностного общения (раппортом) внутри сообщества практики. При этом закрепляющиеся за описываемым дискурсивным событием речевые практики демонстрируют не только значительное отклонение от этикетной вежливости, но и полное пренебрежение ее основными постулатами. В качестве ведущего в исследовании избирается интерпретативный подход к анализу фактического материала, исходящий из так называемой (не)вежливости первого порядка и позволяющий избежать деконтекстуализации фокусной речевой практики - ахиллесовой пяты многих теоретических моделей (не)вежливого речевого поведения. Полученные данные подтверждают необходимость рассмотрения вежливости как контекстно привязанную оценку непосредственными участниками общения поведения друг друга в опоре на бессознательно усвоенные нормы ожидания.

Ключевые слова: речь шафера, сообщество практики, нормы ожидания, конвенции вежливости, невежливость, коммуникативная приемлемость, управление раппортом.
\end{abstract}

\begin{abstract}
British best man speeches, as well as the underlying mechanisms of the best man's communicative choices. Not being subject to any rigid external regulation in the form of set text or etiquette rules, the best man speech, however, invariably shows marked uniformity in terms of the speaker's prevalent discourse choices. In order to identify the discursive norms conventionally associated with British best man speeches, the paper sets out to view the participants of a wedding reception as an emergent community of practice performing in accordance with interiorised and mutually shared
\end{abstract}

(C) Быстрых А. В., Беляева Е. Е., 2021

(i) Контент доступен под лицензией Creative Commons Attribution 4.0 License.

The content is available under Creative Commons Attribution 4.0 License. 
norms of appropriateness which, incidentally, serve as criteria of membership. Drawing on the analysis of 60 British best man speeches (with particular focus on their global scenario, thematic elements, and key discursive strategies), the paper identifies rapport-management tools strategically employed by the best man within the analysed context. The interpretive approach adopted in the study minimizes the risk of overlooking lay conceptualisations of (im) politeness, which is a notable shortcoming of many theoretical models. One noteworthy feature of the findings is that it is only by virtue of context that the identified rapport-management tools are interpretable as polite, which goes to show that linguistic behaviour should not be evaluated as polite unless it conforms to the norms of appropriateness specific to a certain community of practice.

Key words: best man speech, community of practice, discursive norms, politeness conventions, impoliteness, communicative appropriateness, rapport management.

\section{Введение}

Не секрет, что дискурсивная деятельность любого социально интегрированного индивида, помимо прочих коммуникативных практик, с необходимостью предполагает осуществление общественно значимых ритуальных действий, представляющих собой консолидирующий и регулирующий механизм социума и его институтов. При этом в случае реализации жестко регламентированных общественными институтами ритуалов коммуникативная свобода участвующего в них индивида крайне ограничена как в отношении процедурных действий (собственно дискурсивных маневров), так и речевых способов их осуществления. Предметом обсуждения настоящей статьи является степень коммуникативной свободы говорящего, а точнее пределы допустимости его коммуникативных маневров в условиях осуществления менее жестко регламентированного извне ритуала - такого, как речь шафера (best man speech). Опираясь на совершившую в последние десятилетия дискурсивный поворот теорию вежливости [1], мы рассмотрим сформировавшиеся социокультурные и речевые конвенции, предопределяющие дискурсивную специфику данного коммуникативного события в британской языковой культуре, а также определим механизмы формирования данных конвенций как регуляторов речевого поведения индивида в определенном сообществе практики.

Прежде чем рассмотреть механизмы формирования норм вежливости в тех или иных сообществах взаимодействующих индивидов, приведем краткий обзор современных социолингвистических взглядов на феномен ритуала.

Наиболее емкая и утвердившаяся на сегодняшней день в лингвистически ориентированных исследованиях дефиниция ритуала дается В. В. Карасиком, который определяет его как «закрепленную традицией последовательность символически значимых действий» [2, с. 333]. При таком взгляде на дискурсивную природу ритуального события акцентируется утрата конституирующими ритуал речевыми актами своих первичных иллокуций и замещение их условными (социально приписываемыми и одобряемыми) смыслами.
Схожее понимание ритуала находим в работах А. Вежбицкой [3] и Г. Г. Почепцова [4], указывающих, что ритуальное действие происходит в рамках особой ситуации коммуникации, при которой все компоненты речевого взаимодействия обретают некий символический смысл, а также закрепляются в специальных ритуальных знаках. В свою очередь, А. К. Байбурин [5] рассматривает ритуал с точки зрения выработанной обществом практики символического доказательства идентичности социума, которая отличается рекурсивностью и вневременностью. Такой взгляд на ритуал подчеркивает его ключевую роль в обеспечении преемственности социокультурных практик между поколениями коммуникантов.

Уделяя особое внимание степени коммуникативной гибкости сценария ритуала и возможности трансформации закрепляемого за ним текста, М. Г. Извекова выделяет ритуалы жесткого и мягкого типов. «Жесткие» ритуальные тексты не поддаются модификации при изменении событийного контекста. К таким текстам относятся молитвы, брачные клятвы, воинские присяги и т. п. [6]. Характерной чертой соответствующих ритуальных событий является опора на прескриптивные канонические тексты с ограниченным набором лексико-фразеологических средств и реализуемых дискурсивных стратегий.

«Мягкий» тип ритуала может быть соотнесен с коммуникативными событиями, сохраняющими символическую ориентированность и социальную значимость в связи с их ролью в ретрансляции специфичных для лингвокультурного сообщества коллективных ценностей, но не характеризующимися дискурсивной константностью сопровождаемых такие ритуалы текстов. Примером такого события может служить речь шафера. Несмотря на то, что данный социальный ритуал имеет некодифицированный характер, в британской лингвокультуре, как мы покажем далее, формируются особые нормы ожидания в отношении следования шафером неписанным, но закрепившимся в дискурсивной практике конвенциям поведения. При этом отклонение от данных условностей однозначно воспринимается участниками свадебной церемонии как faux pas. 
Вслед за сторонниками дискурсивного подхода к пониманию вежливости $[1 ; 7 ; 8]$ в настоящем исследовании пределы допустимости (уместности) дискурсивных маневров шафера будут описываться нами как ситуативно (контекстно) обусловленные конвенции вежливости в связи с тем, что оценка коммуникативного поведения индивида в терминах вежливо/ невежливо сродни интерпретации его дискурсивных стратегий в терминах уместно/неуместно и является исключительной прерогативой непосредственных участников дискурсивного события, составляющих определенное сообщество практики (community of practice).

Термин «сообщество практики» был введен в научный обиход Э. Венгером [9] для описания процесса социализации индивида (social learning) и объяснения механизмов формирования им социолингвистической (а также широкой социокультурной) компетенции. Сегодня этот термин все чаще используется социологами языка для объяснения факторов, ограничивающих коммуникативную свободу индивида в социальном контексте [10]. Согласно Э. Венгеру, сообщество практики - совокупность людей, объединенных вовлеченностью в совместную деятельность, при этом все, что составляет их практику (ценностные ориентиры, механизмы внутригруппового (в том числе коммуникативного) взаимодействия, механизмы регулирования статусно-ролевых отношений и т. д.), порождается исключительно в процессе совместной деятельности [9, р. 77]. Получается, что члены любого формального или неформального сообщества (рабочий коллектив, спортивная команда, детская группа на игровой площадке и т. д.) вырабатывают свой собственный дискурсивный стиль взаимодействия, опираясь на сформировавшиеся внутри этой группы нормы ожидания. Основными критериями выделения сообщества практики, согласно Э. Венгеру, являются: 1) вовлеченность в совместную деятельность (mutual engagement), предполагающая регулярное взаимодействие членов сообщества; 2) совместная инициатива и нацеленность на решение стоящих задач через согласование вклада каждого члена сообщества (joint negotiated enterprise); 3) дискурсивно формируемый репертуар предпочтительных вербальных и невербальных средств взаимодействия (shared repertoire of negotiable resources accumulated over time) [9].

Осознавая некоторую ограниченность критерия 1 , акцентирующего систематичность взаимодействия членов сообщества практики, и отдавая себе отчет в том, что сообщества практики могут быть эмергентными социальными объединениями, возникающими в актуальных условиях коммуникации на основании наличия у коммуникантов идентичного modus operandi, Э. Венгер в более поздней работе представляет данный критерий в виде «способность продуктивно взаимодействовать с другими членами сообщества» $[11$, p. 226]. В значительной степени такой ракурс на проблему уточнения социальной природы сообщества практики перекликается с концепцией социальных конструктов Р. Уотса, разграничивающего латентные и эмергентные сетевые сообщества (latent and emergent networks), последние из которых создаются в условиях актуальной интеракции на основе наличия у индивида опыта участия в схожих сообществах в прошлом (latent networks) [1].

При описании сформировавшихся в британской лингвокультуре конвенций взаимодействия шафера с аудиторией (молодоженами и гостями торжественного приема на свадебной церемонии) мы будем использовать термин «сообщество практики» в силу того, что он акцентирует разделяемый членами сообщества единый механизм взаимодействия (a way of doing), нежели механизм существования (a way of being). Примечательно, что и Э. Венгер, и Р. Уотс считают, что гармоничное взаимодействие членов выделяемых ими социальных конструктов гарантируется опорой на практически выработанный и интериоризированный (усвоенный) опыт индивида в отношении приемлемых моделей поведения. Наиболее полное воплощение подобный дискурсивно закрепляемый опыт получает в понятии габитуса (habitus) в социально-антропологической концепции П. Бурдьё. По П. Бурдьё, габитус - это набор существующих независимо от воли индивида и усваиваемых в процессе социализации диспозиций (предрасположенностей), склоняющих его к определенным моделям восприятия действительности, мышления и действия [12, p. 12]. Данные диспозиции всегда лежат в основе порождения практик и ориентируют агента на то, чтобы мыслить и действовать в соответствии с интериоризированным опытом. Обращаясь к спортивной метафоре, П. Бурдьё соотносит габитус с игровым чутьем (feel for the game), приобретаемым спортсменом в результате игровой практики, становящимся его второй натурой и играющим ключевою роль в неосознанном регулировании его игровой тактики. Важно, что габитус характеризуется долговечностью (durable), обеспечивающей преемственность поведения индивида; переносимостью (transferable), гарантирующей воспроизведение усвоенной практики в ином опыте; структурированностью (structured), отражающей иерархию социальных отношений в усваиваемом опыте.

Принимая во внимание все сказанное выше, речь шафера будет рассматриваться нами как слабо ритуализированное дискурсивное событие, выстраивающееся на основе социокультурных и речевых конвенций, бессознательно усвоенных участниками данного события и соотносящихся с ситуативно мотивиро- 
ванными нормами вежливости. При этом важно учитывать тот факт, что данные нормы вежливости далеко не всегда доступны третьим лицам (лицам, не входящим в сообщество практики) в силу их некодифицированного характера.

\section{Методология исследования}

Объектом исследования является дискурсивное событие «Речь шафера» в британской лингвокультуре. В свою очередь, предмет исследования представляют дискурсивные и прагмалингвистические характеристики речи шафера в британской языковой культуре в разрезе сформировавшихся конвенций вежливости (коммуникативной уместности).

Цель исследования состоит в определении закрепившихся в дискурсивной практике конвенций вежливости и сложившихся поведенческих норм в отношении композиционной структуры речи шафера, ее тематического наполнения и реализуемых дискурсивных стратегий.

Материалом для исследования послужил корпус, состоящий из 60 текстов речей шафера, извлеченных методом сплошной выборки на сайтах, посвященных организации и проведению свадебных мероприятий (www.hitched.co.uk, www.theknot.com, www.weddingideasmag.com и др.) во временном диапазоне с 1995 г. вплоть до настоящего времени.

Основными методами исследования выступили речеактовый, контекстуальный и дискурсивный анализ. Полученные данные квантитативного анализа позволили верифицировать выводы, сделанные нами на основе интерпретативного подхода к выявлению закрепившихся за речью шафера норм уместности. Данный подход был сознательно выбран нами в качестве предпочтительной альтернативы опросу информантов в связи с тем, что респонденты при внешней установке оценить вежливость тех или иных дискурсивных маневров, как правило, склонны деконтекстуализировать их и игнорировать широкий коммуникативный контекст, играющий решающую роль в восприятии дискурсивной уместности отдельных речевых действий.

\section{Результаты исследования}

\section{Композиционная структура речи шафера}

Несмотря на то, что речи шафера не регламентируются внешними кодифицированными прескрипциями и демонстрируют значительную вариативность формы, исследование собранного корпуса позволило вскрыть однотипность их композиции на уровне глобального сценария. Условно выделенные нами композиционные блоки демонстрируют регулярность в отношении состава речевых актов, конституирующих каждый блок. При этом форма реализации данных речевых актов не обнаруживает каких-либо устойчивых моделей. Данное наблюдение в совокупности с другими заключениями, приводимыми ниже, отчасти объясняет, почему просьба подготовить речь шафера воспринимается в англоязычных культурах многими друзьями жениха как вызов их ораторским способностям: подготовленная речь должна отличаться предельной оригинальностью, прежде всего, формы и в то же время соответствовать исторически закрепившимся в культуре нормам ожидания относительно пределов уместности дискурсивных маневров оратора. В данном случае такой негласной регламентации подвергается конфигурация речевых действий в каждом композиционном блоке.

В целом, инвариантный сценарий речи шафера, как правило, включает в себя три ключевых композиционных блока.

Вступительная часть речи шафера в качестве ядерных иллокуций содержит следующие речевые акты: приветствие, благодарность, комплимент и похвала. Дискурсивно закрепляемые за данным блоком нормы уместности ориентируют шафера на следующие коммуникативные маневры: приветствие публики, проявление благодарности жениху за возможность быть шафером, выражение признательности по отношению к предыдущим ораторам, представление собственной персоны аудитории, выражение одобрения в сторону участника события (невесты, подружек невесты, родителей молодоженов, организаторов праздника) по поводу его поступка, поведения или внешнего вида с целью сокращения социально-психологической дистанции и солидаризации гостей мероприятия как членов единого сообщества практики. Имеющийся у нас корпус контекстов однозначно свидетельствует о том, что сформировавшиеся нормы вежливости обязывают шафера во вступительной части своей речи ставить в приоритет гостей торжественного приема (в том числе за счет смещения фокуса внимания с виновников торжества), например:

1. (Приветствие) Hello everyone and welcome to this special day. I'm so happy it's finally here. (Представление) I'm Brian Cook, Ryan's best man. (Комплимент) I just want to start by pointing out how beautiful all of the bridesmaids look tonight. [www. http://www. hitched.co.uk]

Основная часть речи, как правило, композиционно гомогенна и представляет собой последовательность констативных речевых актов, объединяемых в единый нарративный блок. В соответствии со сформировавшейся конвенцией, приводимое шафером повествование касается потешных (зачастую на грани скабрезности) эпизодов из прошлой жизни жениха, не известных широкой общественности. При этом дискурсивно закрепленная за сообществом практики норма ожидания гостей церемонии в данном 
случае предписывает шаферу поступиться общественно принятыми нормами этики и вынести на широкий круг обсуждения подробности личной жизни жениха до свадьбы. Такой речевой маневр создает эффект «подглядывания в замочную скважину» и является яркой демонстрацией того, насколько дискурсивно подвижным является интерпретация речевого поведения говорящего субъекта с точки зрения его коммуникативной уместности (вежливости).

2. [...] His skills also stretched to the football pitch. Mark was always the most active player on the pitch, always in possession of the ball, although as he was the goalkeeper, it was usually because he was picking it out of the net. If you've ever seen him play, I think you'll agree that his nickname of 'flapper' was quite appropriate.

The step from schoolboy to dysfunctual yob wasn't a big one for Mark, and it wasn't long before he was terrorising the streets of Immingham in his red Astra $\boldsymbol{G T E}$. In fact, people would often remark as he drove by that he looked just like a Hollywood filmstar, only without the suntan... or the muscles... or the good looks... or the style really.

It was Mark's love of Leeds United and beer though that was to be his biggest downfall, to date at least. Picture the scene if you will, it's pre-season, and his team have arranged a friendly with Hull City, in Hull. What better excuse to go to the match, and enjoy a couple of beers with his friends? Everything was going well for the young Mark. He had managed to have his usual 2 pints, and off he set from the pub. It was then that his amazing knack of poor planning kicked in. He suddenly decided that he had to relieve himself there and then. Now most people would have turned around and gone back to the pub, but not our Mark. No, he decided that peeing into a yellow plastic bin in the middle of a busy Hull road at five to three on a Saturday afternoon in a Leeds Utd shirt would be a great idea. [...][www. http://www. hitched.co.uk]

Отметим также, что обширный нарративный элемент в основной части речи шафера, как правило, маркирует переключение говорящего на трансляцию тех компонентов смысла текста, которые М. Халлидэй называл идеационными (ideational) в противовес межличностным (interpersonal) [13], превалирующим в нашем случае во вступительной и заключительной частях. Будучи слабо ритуализированным дискурсивным событием, речь шафера не исчерпывается исключительно символическими речевыми действиями (подверженными десемантизации и ритуализации), а оставляет за говорящим субъектом значительную свободу в трансляции коммуникативно полноценных иллокуций.

Заключительная часть речи ориентирована, прежде всего, на передачу межличностных коммуни- кативных смыслов, представленных такими экспрессивными иллокуциями, как благодарность, похвала, пожелание, тост. Наряду с этим нельзя не отметить, что в данном блоке стереотипно происходит ресинхронизация (realignment) ситуационных и этикетных норм вежливости (cp. all kidding aside), и общий дискурсивный стиль говорящего возвращается в русло публичного выступления церемониального характера, например:

3. ...All kidding aside, (Комплимент) Cara is a smart, beautiful, driven and hardworking young woman, which really compliments Ryan.

While Ryan was away at school, he would come over for supper and spend his time playing with the kids. Someday, hopefully soon, he's going to make a great father, but (Похвала) for now he has the title of the best Godfather to our children.

It's been three years since Ryan stood up as my best man and (Благодарность) I'm honoured to be standing here today. Before getting married, weddings were just a party to eat good food and get drunk but once you've taken vows with someone and decided to spend forever together, going to a wedding means so much more. Love isn't just a feeling, but a commitment too!

(Пожелание) I wish you two a lifetime of health and happiness together. If everyone could raise their glasses... (Tocm) Cheers to Ryan and Cara! [www. http://www. hitched.co.uk]

Заметим при этом, что такой резкий дискурсивный сдвиг в способе поддержания раппорта с аудиторией может показаться нарочито акцентированным (и неуместным) внешнему наблюдателю, но отнюдь не воспринимается как таковой непосредственными членами сообщества практики. Из наших наблюдений следует, что регулярная манифестация этого речевого маневра в речи шафера характеризует его как дискурсивно сформировавшуюся норму вежливости и тем самым отличает речь шафера с точки зрения стереотипно проявляющихся стратегий управления раппортом от других публичных выступлений.

\section{Тематическое наполнение повествования}

Отдельного комментария требуют сформировавшиеся в британской лингвокультуре нормы ожидания участников свадебного торжества в отношении тематического наполнения нарративного блока. Проведенный анализ позволил выявить ряд ключевых тем, к которым шаферы стереотипно обращаются в своей речи: история отношений жениха и невесты (42\%); неприятности и неудачи жениха (40\%); достижения жениха (25\%); знакомство жениха и невесты (23\%); бурная молодость жениха (в том числе в компании шафера) (23\%); детство жениха (20\%); холостяцкие бесчинства на мальчишнике (в том числе со стороны жениха) (17\%) и т. д. Вместе с тем сквозной нитью 
через перечисленные нарративы проходит акцентированная установка говорящего выстраивать повествование вокруг эпизодов прошлой жизни жениха, выставляющих его в нелицеприятном и даже откровенно унизительном свете. Так, следующий контекст наглядно демонстрирует наличие подобной установки в дискурсивном сценарии речи шафера как части британского социокультурного кода в связи с ее эксплицитной вербализацией.

4. We have now reached that pivotal moment in the speech where I am meant - in good taste - to put the groom down. So, minus the good taste, I'll proceed.

The purpose of the best man's speech, or so I've heard, is to embarrass the Groom...well - his real hair colour is ginger - he has a small willy - and a leopard skin thong - which I think is all embarrassing enough.

I remember meeting Tim for the first time, well he just kind of appeared many, many years ago walking... no strutting down the road, skin tight jeans, massive black quiff, sleeves rolled up on his suit jacket and ... Eye liner! Yes Eye liner! Now this was the 80's and Tim being a new romantic-and a trendy one at that-liked to dabble in a bit of make up once and a while. Nothing wrong with that... if you're a woman anyway!!! [www. http:// www.hitched.co.uk]

Как видим, шафер публично транслирует дискредитирующие детали частной жизни жениха в очень колкой и язвительной форме, что, безусловно, в отрыве от контекста посторонними наблюдателями интерпретировалось бы как нарушение норм негативной вежливости, предписывающей говорящему избегать вторжения в частную жизнь собеседника (trespassing on private territory) [14]. Тем не менее в контексте речи шафера подобное «вынесение сора из избы» представляется членам сообщества практики как ожидаемый и всецело одобряемый с их стороны дискурсивный маневр. Нельзя не отметить, что данные наблюдения являются еще одним кирпичиком в фундамент дискурсивно ориентированной концепции вежливости, отвергающей линейную зависимость между этикетной (formulaic) вежливостью и стратегиями гармонизации межличностного общения (раппорта). Другими словами, управление гармонией межличностного взаимодействия (то, что в современных зарубежных исследованиях все чаще описывается термином «relational work» [7]) может производиться на основе полного пренебрежения и даже посягательства на каноны этикета.

Еще один важный аспект описываемой в данном разделе дискурсивно формируемой конвенции в отношении тематического наполнения нарративного блока, который мы не имеем возможности детально обсудить в рамках настоящей статьи, состоит в том, что одобряемые сообществом практики «невежливые» маневры представляют собой так называемую (не)вежливость в отношении третьего лица (third-person (im)politeness) [15] в связи с тем, что жених не является первичным реципиентом речи шафера. Механизмы реализации таких дискурсивных практик отличаются от классических (не)вежливых иллокуций, адресатом которых является непосредственный собеседник, и требуют отдельного анализа.

\section{Дискурсивные стратегии}

Напомним, что одним из критериев выделения сообщества практики, согласно Э. Венгеру, является устойчивый дискурсивно формируемый участниками репертуар предпочтительных коммуникативных маневров. Среди таких неосознанно выбираемых и априори получающих одобрения членами сообщества практики маневров исследователем выделяются: отсутствие преамбул и предисловий, общий фонд историй (local lore) и шуток (inside jokes and knowing laughter), жаргон, языковая экономия (shortcuts to communication) и разделяемые модели речепорождения, отражающие своеобразие мировосприятия [9, p. 130-131]. В сущности говоря, речь идет о закреплении за сообществом практики маркированных для внешнего наблюдателя (и не воспринимаемых таковыми внутри сообщества) дискурсивных стратегиях, предопределяющих специфичные модели речепорождения и речевосприятия. Проведенный анализ британских речей шафера позволил выявить ряд стереотипно реализуемых (и, как покажем далее, зачастую подвергающихся ритуализации) дискурсивных стратегий, которые мы также рассматриваем как компонент норм ожидания соответствующего сообщества практики. При этом важно отметить, что эксплуатируемые шафером дискурсивные стратегии, как правило, не характерны для других публичных речей церемониального характера и характеризуют особый британский социокультурный код, привязанный к соответствующим контекстным условиям.

Отличительной чертой ключевых дискурсивных стратегий, реализуемых в британской речи шафера, является их общая направленность на солидаризацию членов сообщества практики, укрепление внутригруппового единства и усиления ощущения товарищества (camaraderie).

Так, уже отмеченная нами стратегия нарратива (сторителлинга), которая традиционно рассматривается в антропологии коммуникации в качестве цементирующего элемента любого сообщества практики [16], в речи шафера неизменно представлена в форме повествовательного откровения - ретроспективного рассказа о сугубо личных моментах жизни жениха («скелете в шкафу»), например:

5. [...] School was always going to be difficult for someone with Mark's mental age, but he did try his hardest. In fact his Mum kept a few of his old school 
reports, and one that she showed me whilst I was doing some research for this speech clearly stated that Mark was an ideal pupil, who excelled in most subjects.; sorry, I misread that, it actually says that Mark was an IDLE pupil who was EXPELLED from most subjects. [www. hitched.co.uk]

Регулярность обращения к стратегии откровенного повествования в речи шафера ведет к ее ритуализации - конвенциональному использованию, результатом которого является замещение дефолтного коммуникативного смысла символическим (в нашем случае межличностным). В связи с этим, несмотря на то, что вне контекста откровение по поводу частной жизни третьего лица, не являющегося первичным реципиентом дискурса, но присутствующего в ситуации общения, безоговорочно было бы воспринято как конфронтационный дискурсивный маневр, в речи шафера данная речевая стратегия не воспринимается как невежливая и, наоборот, сознательно используется шафером как эффективное средство укрепления гармонии межличностного взаимодействия (за счет вызываемой эмпатиии со стороны гостей церемонии). В основе трансформации коммуникативного эффекта, порождаемого стратегией откровенного повествования в речи шафера, по-видимому, лежит одно прагматическое обстоятельство, характеризующее, согласно У. Лабову, ритуализированную коммуникацию: «[...]в ритуалах мы освобождены от личной ответственности за совершаемые действия» $[17$, р. $352-$ 353]. В самом деле, коммуникант, действующий в условиях ритуализированного события сообразно нормам ожидания конкретного сообщества практики, в первую очередь, опирается на сложившиеся конвенции поведения и, как следствие, пренебрегает рациональной оценкой мотивов совершаемого действия.

Следующая дискурсивная стратегия со стороны шафера, которая так же, как и стратегия откровенного повествования, условно может быть охарактеризована в исследуемом контексте как «безнаказанная невежливость», - это стратегия подтрунивания (banter). Феномен подтрунивания, согласно Дж. Личу, является особой речевой практикой, именуемой им «притворная (наигранная) невежливость» (mock impoliteness) в связи с тем, что внешне невежливые (в том числе крайне оскорбительные) иллокуции не интерпретируются адресатом как таковые [15]. Типичным примером подтрунивания является «дружеская грубость», характеризующаяся обменом оскорбительными репликами в ситуации фамильярного общения.

Анализ имеющихся у нас эмпирических данных позволяет с уверенностью говорить о том, что подтрунивание является дискурсообразующей стратегией британской речи шафера и ключевой составляю- щей его успеха как оратора. При этом в отличие от стратегии повествовательного откровения, мишенью такой внешне коммуникативно амбивалентной дискурсивной практики (ср. предлагаемый для подобных случаев Дж. Калпепером и соавторами термин «противоречивые намеки» (mixed messages) [18]) может быть и жених (контексты 6-8), и гости церемонии (контексты 9-10) ${ }^{1}$.

6. When Joe was a baby, he was so ugly that his mother used to tie a bone around his neck... just so that the dog would play with him. [www.hitched.co.uk]

7. It's fair to say before Stu met Carly, you wouldn't exactly call him Brad Pitt, more like armpit. [www. hitched.co.uk]

8. So, if Laura could just place her hand on the table, Steve if you could put your hand directly on top of hers... How does that feel Steve? I can personally guarantee you that will be the last time you ever have the upper hand so make the most of it while you can! [www.hitched. co.uk]

9. Ladies, gentlemen, friends and freeloaders. It's been a fantastic day so far. The venue is spectacular, the ceremony was very special and everyone looks lovely. [www.hitched.co.uk]

10. To see this many people here at a wedding outside the Metro amazes me, I still can't get over how far people will travel for a free meal and free drinks. [WwW. weddingideasmag.com]

Совершенно очевидно, что усвоенный прошлый опыт взаимодействия шафера и аудитории (габитус) воспроизводится в каждом случае возникновения соответствующего сообщества практики и препятствует интерпретации подобных стратегически выстраиваемых маневров как невежливых. Интересным в данном случае представляется не только факт закрепления данной дискурсивной стратегии за публичной речью церемониального характера (в корне отличающей ее от других публичных выступлений, а также речей шафера в других культурах), но и лежащий в основе данной стратегии механизм солидаризации членов сообщества практики. Известно, что подтрунивание как уместный способ поддержания гармонии межличностной коммуникации, как правило, наблюдается в контексте максимального сокращения и горизонтальной, и вертикальной дистанции между собеседниками [15] особенно при многократ-

${ }^{1}$ Культурно закрепившаяся за шафером практика воздерживаться от условно конфронтационных иллокуций (или допускающих такое толкование на буквальном уровне) в адрес невесты и выбирать в качестве мишени подтрунивания жениха требует отдельного анализа. 
но воспроизводимых взаимодействиях (routinised interaction) [19], а также в ситуациях, где говорящий использует притворную невежливость в отношении собеседника с целью развлечения третьих лиц (ехploitative entertainment) [20]. По-видимому, помимо очевидной установки на то, чтобы продемонстрировать свое остроумие и развлечь аудиторию за счет выставления жениха в качестве объекта насмешек, подтрунивание стереотипно используется шафером как более форсированный (по сравнению со стратегией откровенного повествования) способ солидаризации с аудиторией, поскольку шафер проецирует свой фамильярный стиль взаимодействия с женихом на общение с гостями торжественной церемонии, искусственно преодолевая тем самым социопрагматические барьеры в виде возможной вертикальной и/ или горизонтальной дистанции.

\section{Заключение}

Подытоживая сказанное, приведем наиболее значимые наблюдения, сделанные в ходе исследования.

Несмотря на то, что в британской лингвокультуре речь шафера, будучи слабо ритуализированным дискурсивным событием, не регламентируется внешними кодифицированными прескрипциями, коммуникативные механизмы его реализации демонстрируют значительную однотипность. Предложенный в исследовании подход к описанию и анализу дискурсивно закрепившихся за речью шафера социокультурных и речевых конвенций исходит из рассмотрения участников торжественного приема по случаю бракосочетания как членов сообщества практики - объединения коммуникантов на основе вовлечения в совместную деятельность. При этом в процессе прошлой совместной деятельности формируется уникальный для данного сообщества дискурсивный стиль взаимодействия, стереотипно воспроизводимый в коммуникативной практике между членами сообщества в дальнейшем. Помимо того, что данный дискурсивный стиль является интегральной частью коллективной идентичности членов сообщества практики, он также диктует нормы ожидания в отношении дискурсивно уместных маневров коммуникантов. Данные нормы ожидания описываются в исследовании как дискурсивно сформировавшиеся нормы уместности или речевые конвенции вежливости, разделяемые членами сообщества практики. Демонстрируя значительное отклонение от кодифицированных норм вежливости (этикета), устоявшиеся конвенции в рамках речи шафера, как правило, недоступны внешним наблюдателям, а их знание представляет собой своеобразный критерий членства в сообществе.

Исходя из такого видения социокультурных и речевых конвенций, закрепившихся в британской культуре в отношении речи шафера, был проведен анализ специфичных для данного дискурсивного события норм вежливости, проявляющихся на уровне рассмотрения композиционной структуры речи шафера, ее тематического наполнения и ключевых дискурсивных стратегий в нарративном блоке. Выявленные речевые конвенции кардинально отличают речь шафера от других публичных выступлений церемониального характера и являются частью британского социокультурного кода.

\section{ЛИТЕРАТУРА}

1. Watts R. J. Politeness. New York : Cambridge University Press, 2003. 306 p.

2. Карасик В. И. Языковой круг : личность, концепты, дискурс. М. : Гнозис, 2004. 392 с.

3. Вежбицка А. Речевые жанры // Жанры речи. Саратов : Колледж, 1997. Вып. 1. С. 99-112.

4. Почепцов Г. Г. Теория коммуникации. М. : Рефлбук, 2001. $656 \mathrm{c}$.

5. Байбурин A. К. Ритуал в традиционной культуре. СПб. : Наука, 1993. 240 с.

6. Извекова М. Г. Прагмалингвистические характеристики ритуального дискурса : дис. ... канд. филол. наук. Волгоград, 2006. 204 с.

7. Locher M., Watts R. Politeness theory and relational work // Journal of Politeness Research. 2005. № 1. Pp. 9-33.

8. Mills $S$. Gender and impoliteness // Journal of Politeness Research. 2005. № 1. Pp. 263-280.

9. Wenger E. Communities of Practice : Learning, Meaning, and Identity. Cambridge : University Press, 1998. 318 p.

10. Holmes J., Meyerhoff $M$. The Community of Practice : Theories and methodologies in language and gender research // Language in Society. 1999. № 28. Pp. 173-183.

11. Wenger E. Communities of Practice and Social Learning Systems // Organization. 2000. Pp. 225-246.

12. Bourdieu P. Language and symbolic power. Cambridge : Polity Press, 1991. 292 p.

13. Halliday $M$. Language as social semiotic : The social interpretation of language and meaning. London : Edward Arnold, 1978. 256 p.

14. Brown P., Levinson S. Universals in language usage : Politeness phenomena // Questions and politeness: Strategies in social interaction. Cambridge : Cambridge University Press, 1978. Pp. 56-311.

15. Leech G. Principles of Pragmatics. New York : Longman, 1983. $250 \mathrm{p}$.

16. Westman $P$. "Playing with the Team": The Development of communities of practice in a digital storytelling project // Digital Education Review. 2012. № 22. Pp. 92-100.

17. Labov $W$. Language in the Inner City : Studies in the Black English Vernacular. Oxford : Blackwell, 1976. $440 \mathrm{p}$.

18. Culpeper J., Haugh M., Sinkeviciute V. Impoliteness and mixed messages // The Palgrave handbook of linguistic (im)politeness. London : Macmillan Publishers, 2017. Pp. 322-356. 
19. Bousfield D. Impoliteness in interaction. Amsterdam ; Philadelphia : John Benjamins, 2008. 282 p.

20. Culpeper $J$. Impoliteness and entertainment in the television quiz show : The Weakest Link // Journal of Politeness Research. 2005. № 1. Pp. 35-72.

\section{REFERENCES}

1. Watts R. J. Politeness. New York: Cambridge University Press, 2003.

2. Karasik V. I. Yazykovoj krug: lichnost', koncepty, diskurs [Linguistic circle: person, concepts, discourse]. Moscow: Gnosis, 2004.

3. Wierzbicka A. Rechevye zhanry [Speech genres]. In: Zhanry rechi. Saratov: College, 1997. Issue 1. Pp. 99-112.

4. Pocheptsov G. G. Teoriya kommunikacii [Communication theory]. Moscow: Refl-book, 2001.

5. Bajburin A. K. Ritual v tradicionnoj kul'ture [Ritual in traditional culture]. Saint-Petersburg: Nauka, 1993.

6. Izvekova M. G. Pragmalingvisticheskie harakteristiki ritual'nogo diskursa [Pragmalinguistic features of ritual discourse]. PhD Dissertation. Volgograd, 2006.

7. Locher M. Politeness theory and relational work. In: Journal of Politeness Research. 2005. No. 1. Pp. 9-33.

8. Mills S. Gender and impoliteness. In: Journal of Politeness Research. 2005. No. 1. Pp. 263-280.

9. Wenger E. Communities of Practice: Learning, Meaning, and Identity. Cambridge: University Press, 1998.

10. Holmes J., Meyerhoff M. The Community of Practice: Theories and methodologies in language and gender research. In: Language in Society. 1999. No. 28. Pp. 173-183.

Воронежский государственный университет

Быстрых А. В., кандидат филологических наук, доиент кафедры английской филологии

E-mail: andy0210@yandex.ru

Беляева Е. Е., магистрант

E-mail: edi5510@yandex.ru

Поступила в редакциию 13 сентября 2021 г.

Принята к публикаџии 15 октября 2021 г.

\section{Для циитирования:}

Быстрых A. В., Беляева Е. Е. Сообщество практики как источник дискурсивно формируемой нормы (на примере британской речи шафера) // Вестник Воронежского государственного университета. Серия: Лингвистика и межкультурная коммуникация. 2021. № 4. C. 81-89. DOI: https://doi.org/10.17308/lic.2021.4/3814
11. Wenger E. Communities of Practice and Social Learning. In: Organization. 2000. Pp. 225-246.

12. Bourdieu P. Language and symbolic power. Cambridge: Polity Press, 1991.

13. Halliday M. Language as social semiotic: The social interpretation of language and meaning. London: Edward Arnold, 1978.

14. Brown P., Levinson S. Universals in language usage: Politeness phenomena. In: Questions and politeness: Strategies in social interaction. Cambridge: Cambridge University Press, 1978. Pp. 56-311.

15. Leech $\mathrm{G}$. The pragmatics of politeness. New York: Oxford University Press, 2014.

16. Westman P. "Playing with the Team": The Development of communities of practice in a digital storytelling project. In: Digital Education Review. 2012. No. 22. Pp. 92-100.

17. Labov W. Language in the Inner City: Studies in the Black English Vernacular. Oxford: Blackwell, 1976.

18. Culpeper J., Haugh M., Sinkeviciute V. Impoliteness and mixed messages. In: The Palgrave handbook of linguistic (im)politeness. London: Macmillan Publishers. 2017. Pp. 322-356.

19. Bousfield D. Impoliteness in interaction. Amsterdam ; Philadelphia: John Benjamins, 2008.

20. Culpeper J. Impoliteness and entertainment in the television quiz show: The Weakest Link. In: Journal of Politeness Research. 2005. No. 1. Pp. 35-72.

Voronezh State University

Bystrykh A. V., Candidate of Philology, Associate Professor of the English Philology Department

E-mail: andy0210@yandex.ru

Belyaeva E. E., Master-student

E-mail: edi5510@yandex.ru

Received: 13 September 2021

Accepted: 15 October 2021

\section{For citation:}

Bystrykh A. V., Belyaeva E. E. The community of practice as a framer of discursive norms (case study: best man speech). Proceedings of Voronezh State University. Series: Linguistics and Intercultural Communication. 2021. No. 4. Pp. 81-89. DOI: https://doi.org/10.17308/lic.2021.4/3814 